\title{
Study on the Effect of Load Imbalance on the Actual Operation of Ground Coupled Heat Pump
}

\author{
Yi MAN ${ }^{1,2, a,{ }^{*}}$, Tian-Tian DU ${ }^{1, b}$, Ze-Jiang WANG ${ }^{1, c}$, Guo-Xin JIANG ${ }^{1, d}$, \\ Sheng-Yu SHI ${ }^{1, e}$ and Liang WANG ${ }^{1, \mathrm{f}}$ \\ ${ }^{1}$ School of Thermal Engineering, Shandong Jianzhu University, Jinan, China, \\ ${ }^{2}$ Key Laboratory of Renewable Energy Technologies for Buildings (Shandong Jianzhu University), \\ Ministry of Education, Jinan, China \\ a manyilaura@163.com, b 18766110679@163.com, ' $41875877 @ q q . c o m$ \\ ${ }^{*}$ Corresponding author
}

Keywords: Load imbalance, Ground coupled heat pump, Actual operating performance.

\begin{abstract}
In the practical application of the ground coupled heat pump project, when the heat extracted from the soil does not match the heat released to the soil, it will cause the load imbalance and the change of soil temperature, which will lead to the gradual decrease of the operating efficiency of the heat pump unit and even the failure to operate normally. Aiming at the problem of load imbalance commonly existing in the heat load dominated ground coupled heat pump project, this paper takes a ground coupled heat pump project in Rizhao city of Shandong province as an object. Through sorting out its long-term operating data, emphatically analyzes the system load imbalance rate and the influence of load imbalance on the actual operation of the system, and puts forward feasible solutions.
\end{abstract}

\section{Introduction}

In China, which is in the process of modernization, energy and environment issues have become two important issues that need to be solved urgently [1].With the change of industrial structure, the energy consumption of HVAC in our country accounts for 30\%-50\% of the building energy consumption. Therefore, using renewable energy to reduce HVAC energy consumption is the most effective way to achieve energy conservation and emission reduction [2].

Ground coupled heat pump is an energy-saving and environmental protection technology that effectively uses shallow ground energy and has been popularized and applied at home and abroad. However, due to the lack of records of the operating data of the ground coupled heat pump system, the current research focuses on system simulation. In cold regions and cold regions, the load imbalance is generally manifested as: the amount of heat extracted from the soil is much greater than the amount of heat released to the soil $[3,4]$. In addition, the operation control mode of the ground coupled heat pump system is unreasonable, which will also cause the phenomenon of load imbalance.

Through collecting and sorting out the long-term operating data of a ground coupled heat pump system in Rizhao city, Shandong province, this paper analyzes the load imbalance rate of the system and the influence of the load imbalance on the actual operating performance of the system, and puts forward corresponding solutions.

\section{General Situation of Actual Ground Coupled Heat Pump Project}

The ground coupled heat pump system project is located in a campus in Rizhao city. The project uses part of the planned greenbelt landscape site to install the ground heat exchanger. The project plans to service 11 buildings with $109750 \mathrm{~m}^{2}$ air conditioning areas, which includes the training building, apartment building, teaching building and service training building. 


\section{Analysis of Soil Characteristics}

According to the geotechnical thermal response test report of the project site, the comprehensive ground thermal conductivity is $2.043 \mathrm{~W} / \mathrm{m}^{\circ} \mathrm{C}$, which is relatively high.

\section{Design Parameters of Ground Coupled Heat Pump System}

\section{Design of Ground Heat Exchanger}

According to the <technical specification for ground source heat pump system engineering > (GB 50366 - 2009), the design of ground heat exchanger were carried out based on the theory of line heat source. 630 boreholes with 100 meters depth and 5 meters borehole spacing were selected, and double U-shaped pipes were buried inside boreholes.

\section{Terminal System Design}

Considering different functions of buildings, various terminal methods are adopted inside buildings. The details are as follows:

(1) The comprehensive teaching building and the service industry training center building adopt fan coil units for cooling and heating provision;

(2) Conventional Radiators are installed in the training center building and multi-storey apartment buildings for heating provision in winter, and there is no demand for cooling in summer;

(3) High-rise apartment buildings use floor radiator to provide heating in winter, and use floor-installed fan coil unit to provide cooling in summer. These two terminal types are connected by a three-way valve.

\section{Selection of System Heat Pump Unit}

Considering the comprehensive performance-price ratio, three water (ground) source heat pump units with refrigerating capacity of $1097 \mathrm{~kW}$, heating capacity of $1239.4 \mathrm{~kW}$ are selected. The temperature of cold water supply and return cold water in summer is $7 / 12^{\circ} \mathrm{C}$, and the temperature of hot water supply and return hot water in winter is $50 / 45^{\circ} \mathrm{C}$.

\section{Dynamic Simulation of Actual Engineering Load}

The results of the dynamic load simulation analysis of a typical comprehensive teaching building are plotted in Fig. 1.

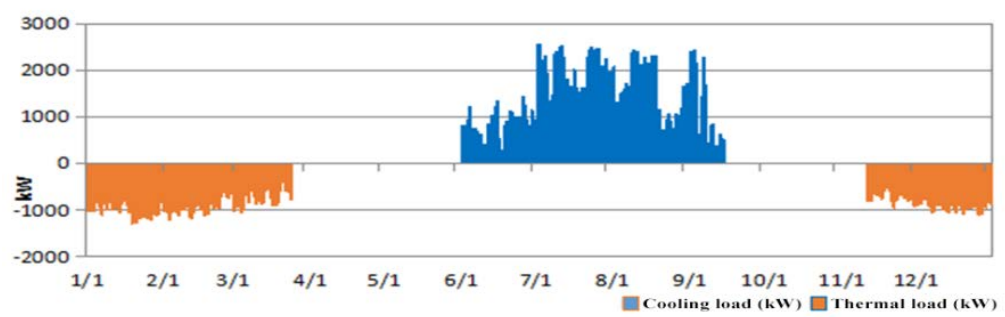

Fig. 1 Dynamic load simulation

\section{Analysis of Load Imbalance}

\section{Analysis of Load Imbalance under Design Conditions}

According to simulation results of the building load bear by the ground coupled heat pump system, the heat released to the ground and extracted from the ground by the heat pump unit can be calculated for the whole year (within one operation cycle), as shown in Table 2. 
Table 1 Calculation results of ground heat transfer load

\begin{tabular}{cc}
\hline Heat released to the ground $(\mathrm{kW} \cdot \mathrm{h})$ & 3360168 \\
\hline Heat extracted from the ground $(\mathrm{kW} \cdot \mathrm{h})$ & 3077461 \\
\hline Unbalance rate & $8.4 \%$ \\
\hline
\end{tabular}

From the calculation, it can be seen that the load unbalance rate of the soil is $8.4 \%$ in one operation cycle, and the heat extracted from the soil can basically balanced the heat released to the soil of the heat pump unit are basically balanced.

\section{Analysis of Actual Operating Load Imbalance}

In actual use, in order to save operating costs and other purposes, the operator has made the ground coupled heat pump system bear part of the additional load, making the heating area reach 109750 $\mathrm{m}^{2}$. The actual heating and cooling loads borne by the system is shown in Table 2 .

Table 2 Actual heating and cooling loads borne by the system

\begin{tabular}{ccccc}
\hline Buildings & Area $\left(\mathrm{m}^{2}\right)$ & Air conditioning system & $\begin{array}{c}\text { Heating } \\
\text { load(KW) }\end{array}$ & $\begin{array}{c}\text { Cooling } \\
\text { load(KW) }\end{array}$ \\
\hline B1 & 19726 & Fan coil & 888 & 1578 \\
\hline B2 & 24131 & Radiator & 1086 & 0 \\
\hline B3 & 2678 & Fan coil & 121 & 121 \\
\hline B4 & 17183 & Radiator & 773 & 0 \\
\hline B5 & 46032 & Floor heating + fan coil & 1298 & 2071 \\
\hline Total & 109750 & & 4166 & 3770 \\
\hline
\end{tabular}

Notes: B1 for teaching building; B2 for training center; B3 for service training building; B4 for multi-storey apartment building; B5 for high-rise apartment building

Under summer running condition, the operator only utilize one circulating water pump to circulate the water flow between the ground heat exchanger and the terminal to realize "free cooling" with water flow of $245 \mathrm{~m}^{3} / \mathrm{h}$ and temperature difference of $2{ }^{\circ} \mathrm{C}$. The circulating pump turned off during the school summer vacation. Based on calculation, the average heating load in heating season is $2146.7 \mathrm{~kW}$, and the average heat flux extracted from ground is $1610 \mathrm{~kW}$. The average cooling load in the cold season is $570 \mathrm{~kW}$ and the average heat flux released to the ground is $570 \mathrm{~kW}$ (ignoring the power of the circulating pump). Multiplied by the system operating time during heating and cooling season, the actual heat exchange load of ground heat exchanger can be obtained, as shown in Table 3.

Table 3 Actual ground heat transfer load

\begin{tabular}{cc}
\hline Heat released to the ground $(\mathrm{kW} \cdot \mathrm{h})$ & 1038680 \\
\hline Heat extracted from the ground $(\mathrm{kW} \cdot \mathrm{h})$ & 4636800 \\
\hline Unbalance rate & $77 \%$ \\
\hline
\end{tabular}

Under the cooling provision of summer, because the long summer vacation and the low occupancy rate of buildings is relatively low, the actual cooling load in summer is far less than the design value. Under heating provision of winter, the actual heating load is greater than the design value because the operator has expanded the heating area of the system. Therefore, the load imbalance rate of the ground coupled heat pump system in actual operation is as high as $77 \%$. 


\section{System Operation Data}

\section{Data Sources}

The data collected in this paper are provided by the operator of the ground coupled heat pump project. The collected data include four heating seasons and four cooling seasons from 2013 to 2017.The operating data at system startup were not included in the statistical range when data were compiled. The average temperature of borehole wall during four years' operation is shown in Fig. 2.

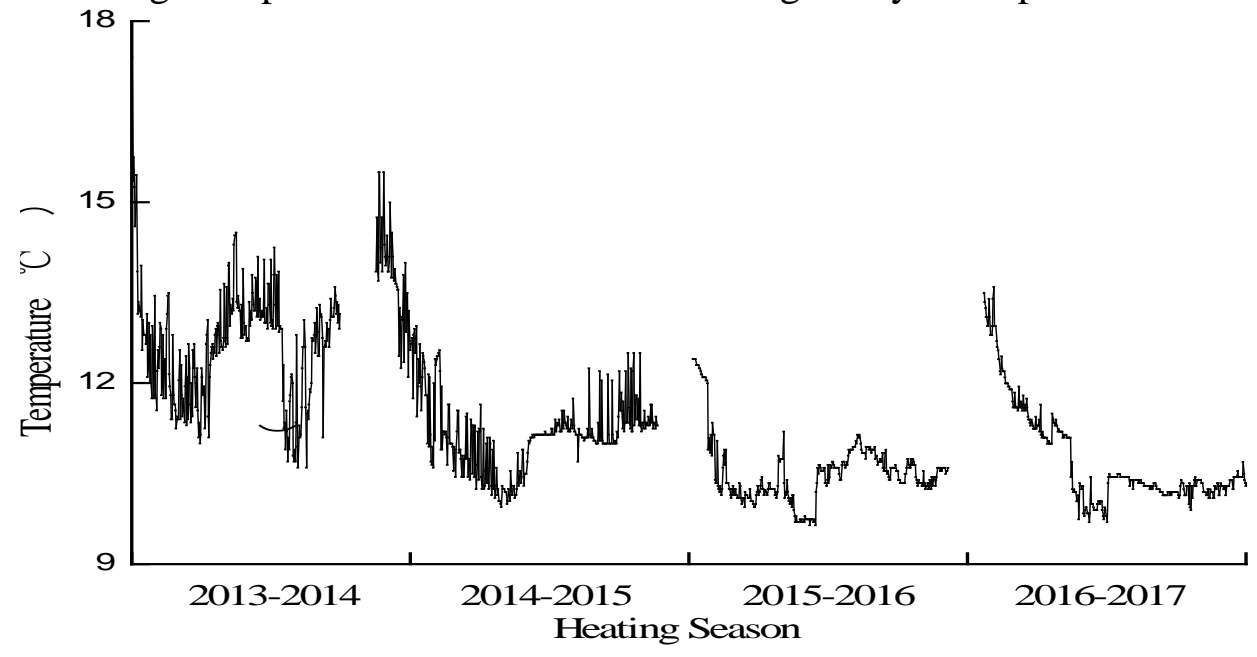

Fig. 2 Change trend of soil coupled temperature in 2013 - 2017

\section{Operation Data of Heat Pump During Heating Provision Period}
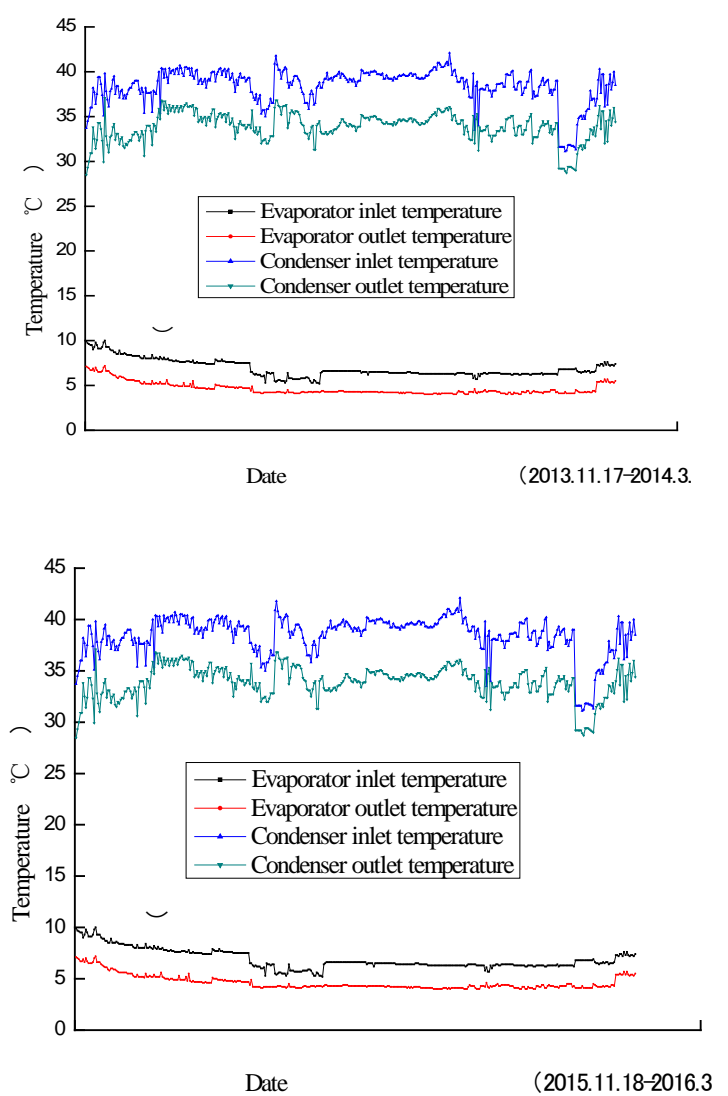
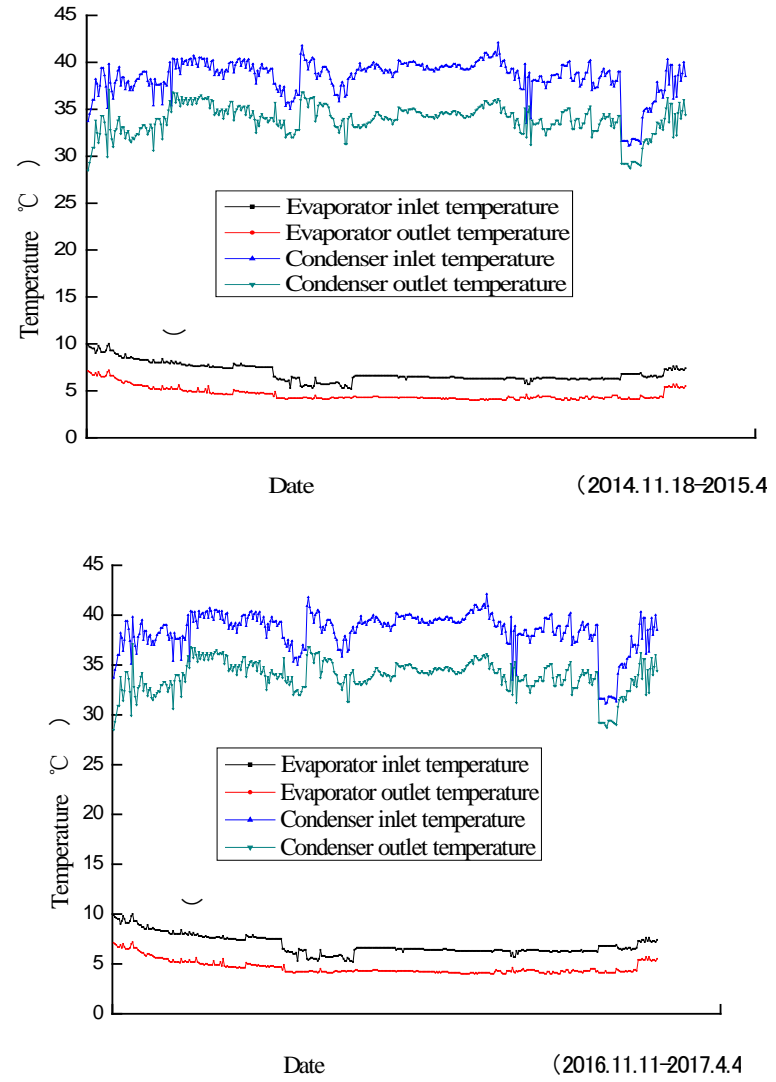

Fig. 3 Operation data of heat pump unit in heating season 2013 - 2017

Up till now, the ground coupled heat pump system has been operated stably for five years. Figure 3 shows the operating data of the heat pump unit during the heating season from November 2013 to April 2017.It can be seen that during heating operation, the water temperature at the evaporator 
outlet of the heat pump unit is basically maintained at about $40^{\circ} \mathrm{C}$. With a terminal system in the form of floor heating plus fan coil, the user can obtain better heating effect to ensure the basic heating demand in winter.

During the heating period when the heat pump unit was put into use in November 2013, the change trend of ground temperature was relatively gentle. In the following three heating seasons, the change of ground temperature is relatively drastic. Obviously, under the condition of serious load imbalance, the ground temperature has a significant downward trend with an increase downward rate along with the system operation.

\section{Feasible Solutions to Load Imbalance}

(1) Heat can be supplied to the ground by circulating waste hot water in the ground heat exchanger during the transitional season to avoid load imbalance.

(2) Use other available heat sources to bear part of the heat load, and reduce the amount of heat extracted from the ground in winter so as to achieve load balance.

(3) Increase the air conditioning area of free cooling provided by the system in summer to increase the amount of heat released to the ground in summer so as to balance the heat exchange of the ground throughout the year.

\section{Conclusion}

(1) During the actual use of the ground coupled heat pump system, due to improper operation and management, the load imbalance rate of ground is as high as $77 \%$.According to the actual system operation parameters during four years' running, the load imbalance has led to the decline of ground temperature and the performance of the heat pump unit. It can be judged that after the long-term operation of the system, the load imbalance will continue to accumulate, the ground temperature will obviously decrease, and the unit's energy efficiency will drop and even failed to provide heating in winter.

(2) For this type of ground coupled heat pump project with predominant heating load, it is possible to supply waste heat to the ground, to use other heat sources to bear part of the heating load, and to increase the summer cooling load borne by the system.

(3) In the promotion of ground coupled heat pump technology, reasonable design and operation strategies must be formulated based on comprehensive consideration of load characteristics, local ground thermal properties, climate characteristics and system operation reliability requirements, to avoid the load imbalance problem and to ensure the long-term system operation performance.

\section{Acknowledgement}

This research was financially supported by a grant from Shandong Province Natural Science Foundation (No. BS2015NJ016), and a grant from Shandong Province Green Building Collaborative Innovation Centre Team Building Foundation (No. LSXT201502).

\section{References}

[1] Laiyun Sheng. China statistical yearbook 2011[M]. Beijing: China statistical publishing house, 2012.

[2] Liu L, Zhao J, Liu Z, et al. Energy consumption comparison analysis of high energy efficiency office buildings in typical climate zones of China and US based on correction model[J]. Energy, 2014, 65(1); 221-232.

[3] Wu W, Wang BL, You T. A potential solution for thermal imbalance of ground coupled heat pump systems in cold regions: Ground coupled absorption heat pump [J]. Renew Energy, 2013, 59:39-48. 
[4] Fan R, Jiang YQ, Yao Y, et al. Theoretical study on the performance of an integrated ground-coupled heat pump system in a whole year [J]. Energy, 2008, 33(11): 1671-16. 